\title{
GESTÃO E INDICADORES DE ABASTECIMENTO DE ÁGUA NO SETOR URBANO DE LAGOA REAL - BAHIA
}

Management and indicators of water supply in the urban area of Lagoa Real - Bahia

Gestión e indicadores de abastecimiento de agua en el sector urbano de Lagoa Real - Bahia

Tadeus Dias Duca ${ }^{1}$

Junívio da Silva Pimentel ${ }^{2}$

\footnotetext{
${ }^{1}$ Licenciado em Geografia pela UNEB - Universidade do Estado da Bahia, Mestrando em Geografia, UESB - Universidade Estadual do Sudoeste da Bahia - E-mail: td.duca@yahoo.com.br;

${ }^{2}$ Professor assistente do curso de Licenciatura em Geografia da UNEB - Universidade do Estado da Bahia, Campus VI E-mail: juniviopimentel@yahoo.com.br;
}

\begin{abstract}
Resumo
O presente artigo visa refletir acerca do uso e gestão dos recursos hídricos tendo como foco o abastecimento urbano da cidade de Lagoa Real-Bahia. Para tanto, fez-se uso do método hipotético-dedutivo, o qual possibilita inferências particulares partindo de uma realidade mais geral. A primeira etapa da pesquisa compreende a construção da bibliografia básica, seguida da aquisição de dados secundários, disponíveis no Sistema Nacional de Informações sobre Saneamento (SNIS). Por fim, tem-se a seleção/tratamento dos dados e redação do material. A partir da análise da área de estudo, verificou-se que parte dos princípios legais não são aplicados, principalmente no que se refere à informação e comunicação, garantia de qualidade e quantidade de água disponível a população urbana.
\end{abstract}

Palavras-chave: Abastecimento urbano; Gestão; Recursos hídricos.

\begin{abstract}
This article aims to reflect on the use and management of water resources, focusing on the urban supply of the city of Lagoa Real-Bahia. For that, the hypothetico-deductive method was used, which allows for particular inferences from a more general reality. The first stage of the research comprises the construction of the basic bibliography, followed by the acquisition of secondary data, available in the National Sanitation Information System (SNIS). Finally, one has the selection / treatment of the data and writing of the material. From the analysis of the study area, it was verified that some of the legal principles are not applied, mainly about information and communication, quality assurance and quantity of water available to the urban population.
\end{abstract}

Keywords: Urban supply; Management; Water resources.

\section{Resumen}

El El presente artículo tiene por objeto reflexionar sobre el uso y gestión de los recursos hídricos teniendo como foco el abastecimiento urbano de la ciudad de Lagoa Real-Bahía. Para ello, se hizo uso del método hipotético-deductivo, el cual posibilita inferencias particulares partiendo de una realidad más general. La 
primera etapa de la investigación comprende la construcción de la bibliografía básica, seguida de la adquisición de datos secundarios, disponibles en el Sistema Nacional de Información sobre Saneamiento (SNIS). Por último, se tiene la selección / tratamiento de los datos y redacción del material. A partir del análisis del área de estudio, se verificó que parte de los principios legales no son aplicados, principalmente en lo que se refiere a la información y comunicación, garantía de calidad y cantidad de agua disponible para la población urbana.

Palabras clave: Abastecimiento urbano; Gestión; Recursos hídricos

\section{Introdução}

Na perspectiva de utilização dos recursos naturais de forma comedida e/ou racional surgem estudos relacionados à gestão dos recursos hídricos que ganharam maiores proporções a partir da década de 1990. Isso se deve, dentre outros fatores; os impactos ambientais compreendidos na intervenção antrópica no meio ambiente (a urbanização compõe-se como parte desse processo) e a manutenção da vida e reprodução de relações, principalmente econômicas, que se desenvolvem em âmbito social.

A gestão dos recursos hídricos se constitui como prática a se desenvolver no intuito de defesa e orientação quanto às múltiplas formas de utilização das águas, tendo em vista o estabelecimento de níveis de quantidade e qualidade de recursos para as gerações presentes e futuras. Nesse sentido, com foco no abastecimento urbano de água, entende-se que as Leis federais: Lei $n^{\circ}$ 9.433/1997 e Lei n 11.445/2007 são importantes no que concerne o estabelecimento de princípios para a gestão e utilização racional das águas.

A Lei $n^{\circ}$ 9.433/1997 estabelece a criação do Sistema Nacional de Gerenciamento de Recursos Hídricos (SINGREH). Essa lei apresenta os fundamentos inerentes a Política Nacional dos Recursos Hídricos (PNRH), donde se tem os princípios básicos no que concerne a utilização da água.

No sentido de gestão hídrica municipal, além das políticas estabelecidas a nível local, destaca-se como instrumento de gestão das águas, principalmente para os municípios que não dispõem de leis próprias, a necessidade de elaboração e efetivação do Plano Municipal de Saneamento Básico (PMSB), instituída segundo a Lei $\mathrm{N}^{\circ}$ 
11.445/2007, esse plano torna-se importante, pois "todas as prefeituras têm obrigação de elaborar seu Plano Municipal de Saneamento Básico (PMSB) ${ }^{3 \%}$.

Mediante as diferentes formas de apropriação e emprego das águas, realizadas pela sociedade e atividades por ela desenvolvida é que emerge a necessidade de repensar os recursos de forma racional e estratégica. Considera-se ainda as peculiaridades ambientais, com destaque para variabilidade das observáveis atmosféricas que se comportam de maneira a imprimir condições características e particulares para cada região.

A área em exame compreende a instância urbana do município de Lagoa Real, município este, situado na Região do Sertão Produtivo ${ }^{4}$ e faz parte da bacia do Grande Rio de Contas.

A validade da pesquisa é entendida mediante sua verificação e análise a nível acadêmico, bem como a nível local na instância pesquisada, uma vez que são escassas as produções e registros sistemáticos no intuito de entendimento das relações de gestão hídrica, assim como de abastecimento urbano. As condições relativas à problemática em exposto vêm a refletir diretamente na população local, pois a água é usada, genericamente, nas mais diversas tarefas cotidianas: consumo humano, limpeza de vestuário, higiene pessoal, entre outros.

O presente trabalho, objetiva visa refletir acerca do uso e gestão dos recursos hídricos tendo como foco o abastecimento urbano da cidade de Lagoa Real - Bahia. Para tanto, tem-se como objetivos secundários: identificar as disposições legais e diretrizes no que se refere aos princípios de gestão hídrica brasileira; esboçar um panorama sobre o abastecimento urbano.

Para a presente pesquisa, utilizou-se o método hipotético-dedutivo, o qual trabalha sob a perspectiva de apresentação de um panorama geral sobre uma situação/problema que, através de sua generalidade, pode estabelecer as bases para explicação de estruturas mais particulares. Dessa forma, a perspectiva questionadora deste trabalho compreende o entendimento da seguinte afirmação: se a gestão dos recursos hídricos influi diretamente na relação entre disponibilidade/qualidade da água, e levando em consideração que o abastecimento urbano se apresenta enquanto elemento

\footnotetext{
${ }^{3}$ Texto extraído da pagina da Sanepar, pagina inicial seção prefeituras, disponível em: http://site.sanepar.com.br/prefeituras/plano-municipal-de-saneamento-basico

${ }^{4}$ Instituída mediante o Decreto ${ }^{\circ} 12.354$ de 25 agosto de 2010, o Programa Territórios de Identidade. Segundo o Artigo $1^{\circ}$ da mesma lei, tal programa tem por finalidade "colaborar com o panorama do desenvolvimento econômico e social dos Territórios de Identidade da Bahia, em consonância com os programas e ações dos governos federal, estadual e municipal" (BAHIA, 2010).
} 
relacionado a tais políticas entende-se que, as ações implicadas na lógica de gestão são essenciais para a efetiva qualidade e disponibilidade de água.

A pesquisa foi iniciada mediante o levantamento bibliográfico base para a investigação, seguido pela aquisição de dados secundários necessários para as discussões a serem constituídas. Nesse sentido, optou-se pela utilização, em maior parte, dos dados cadastrados no Sistema Nacional de Informações sobre o Saneamento (SNIS).

Com o auxílio da bibliografia anteriormente levantada e de textos posteriormente localizados, construiu-se a base teórica da pesquisa. Os dados, por sua vez, foram selecionados e trabalhados no sentido de elaboração de gráficos. Por fim, foram realizadas as análises finais, bem como organização e correção do presente material.

\section{Gestão e racionalização dos recursos naturais/hídricos}

O Brasil apresenta um complexo arranjo natural onde se encontram regiões com maior ou menor disponibilidade e acesso à água. Os fatores para tal situação são diversos, indo desde questões climáticas, de conservação, assim como poluição de corpos hídricos. Os países de maior disponibilidade hídrica de superfície e subterrânea são geralmente os que dispõem de dimensões continentais e de climas tropicais, o Brasil é caso claro nesse aspecto, uma vez que, segundo dados do IBGE (2010), possui extensão territorial de aproximadamente $8.515 .767,049 \mathrm{~km}^{2}$ e conta ainda com reservatórios subterrâneos e bacias hidrográficas de dimensões expressivas. No Brasil, os principais climas são: equatorial (floresta amazônica), tropical (faixa costeira: mangue e mata atlântica; na parte centro-nordeste: cerrado), semiárido (caatinga), subtropical (pampa e mata de araucárias).

Reconhecendo a água como indispensável à sobrevivência da espécie humana, tanto na instância biológica quanto social, e valendo-se da premissa de que ela não é um bem infinito. Historicamente deu-se a necessidade de criação de meios de gerência dos recursos susceptíveis as ações antrópicas e de suas consequências. Dessa forma, convencionou-se a chamar de recursos hídricos toda a água disponível econômica e tecnicamente aos homens. Como afirma Pereira Júnior (2004)

A parcela renovável de água doce da Terra é de cerca de $40.000 \mathrm{~km}^{3}$ anuais, correspondendo à diferença entre as precipitações atmosféricas 
e a evaporação de água sobre a superfície dos continentes. Nem todo esse volume, entretanto, pode ser aproveitado pelo homem. Quase dois terços retornam rapidamente aos cursos de água e aos oceanos, após as grandes chuvas. O restante é absorvido pelo solo, permeando suas camadas superficiais e armazenando-se nos aquíferos subterrâneos, os quais, por sua vez, serão as principais fontes de alimentação dos cursos de água durante as estiagens. A parcela relativamente estável de suprimento de água é, portanto, de pouco menos de $14.000 \mathrm{~km} 3$ anuais. Essa parcela de água doce acessível à humanidade no estágio tecnológico atual e a custos compatíveis com seus diversos usos é o que se denomina "recursos hídricos". (PEREIRA JUNIOR, 2004, p. 3).

Rebouças (1999) complementa esse raciocínio e conclui que,

Embora usado muitas vezes como sinônimo existe uma diferença conceitual entre água e recurso hídrico. O termo água remete ao elemento natural, desvinculado de qualquer uso. Já o termo recurso hídrico considera a água como um bem econômico apropriado pelo homem, passível de utilização com determinado fim (REBOUÇAS apud MIRANDA, 2012, p. 20).

Tem-se então uma necessidade fundamental para gerência dos recursos hídricos, ela perpassa pela compreensão dos mecanismos de exploração e organização dos recursos naturais dentro de um espaço delimitado, onde se faz necessário o entendimento dos elementos que interferem na dinâmica ambiental. Sendo assim,

Todo recurso hídrico é água, mas nem toda água é recurso hídrico; nem sempre seu uso possui viabilidade econômica. A apropriação da água para atingir um fim nas atividades econômicas e no trabalho envolve sua transformação em bem econômico, que passa a ser considerado como recurso hídrico (ROCHA et al, 2011, p. 30).

A gestão torna-se uma das palavras-chave nesse cenário, isso por representar o pensar, e consequentemente, o agir sobre a realidade que é dotada de relações sociais, econômicas e políticas por vezes contraditórias. Parte dessa preocupação pode ser mais bem entendida uma vez considerando a criação/aperfeiçoamento de programas/instituições/políticas de acompanhamento e estudos voltados a construção de soluções eficientes e sustentáveis para a gestão dos recursos hídricos, como destaca a Associação Brasileira de Recurso Hídricos (ABRH):

Até recentemente, principalmente em nosso país, a água era considerada como um recurso natural renovável, em geral farto e abundante, e que poderia atender, sem restrições, a quase todas as necessidades que dele viessem a ser requeridas. Sua carência era sentida apenas nas regiões semiáridas, fato considerado grave, mas natural. Entretanto, a partir da Conferência de Dublin, em janeiro de 1993, a água passou a ser considerada como um recurso finito e, 
sobretudo, vulnerável. Fundada em 1977, a Associação Brasileira de Recursos Hídricos - ABRH, vem acompanhando, estimulando e participando do despertar da sociedade brasileira para este problema (ABRH, 2014) $)^{5}$.

Dentre os vários elementos imbricados no sentido de estabelecimento de uma gestão hídrica eficiente para a área a ser estudada, destaca-se uma inclinação inicial para a realidade do quadro natural das regiões semiáridas, caracterizadas, dentre outras coisas, pela baixa pluviosidade média anual, e consequentemente menor disponibilidade hídrica frente a outras realidades vistas no Brasil e mesmo no mundo. De maneira simples, entende-se que apesar de ser compreendido como natural tal componente revela-se como foco de preocupação.

$\mathrm{O}$ ato de gerir está intimamente ligado com o preceito de planejamento que, dentre outros aspectos, busca a utilização plena dos recursos hídricos, dessa forma, o gerenciamento deve ser eficiente e preconiza o desenvolvimento socioeconômico, alinhado à postura de proteção dos sistemas naturais, considerados como frágeis e de vital importância para qualquer sociedade (ROCHA, 2011).

Estudos relacionados a gestão dos recursos hídricos a nível global ganharam maior destaque a partir da Conferência Internacional de Água e Meio Ambiente, realizada em Dublin, Irlanda no ano de 1992 (DECLARAÇÃO DE DUBLIN, 1992). Essa conferência parte da ideia de que o mau uso e a escassez da água doce representam riscos aos ecossistemas, desenvolvimento industrial, saúde, bem-estar, dentre outros elementos.

Diante dessa situação, estabeleceram-se a partir dessa conferência quatro princípios básicos mundiais de orientação quanto à utilização da água, sendo eles:

$1^{\circ}$ - A água doce é um recurso finito e vulnerável, essencial para sustentar a vida, o desenvolvimento e o meio ambiente;

$2^{\circ}$ - Gerenciamento e desenvolvimento da água deverão ser baseados numa abordagem participativa, envolvendo usuários, planejadores legisladores em todos os níveis;

$3^{0}$ - As mulheres formam papel principal na provisão, gerenciamento e proteção da água;

$4^{\mathrm{o}}$ - A água tem valor econômico em todos os usos competitivos e deve ser reconhecida como um bem econômico.

\footnotetext{
${ }^{5}$ Texto extraído da pagina ABRH, seção ABRHidricos, disponível em: http://www.abrh.org.br/SGCv3/index.php?P1=2\&P2=3
} 
Tais princípios foram responsáveis por uma série de avanços no tocante à gestão hídrica e influenciaram diretamente a legislação específica de diversos países, como é o caso do Brasil.

O estabelecimento dos referidos princípios faz-se importante para a gestão dos recursos hídricos, uma vez que, leva-se em consideração a finitude da água implica diretamente em políticas e práticas que se concretizem na plena utilização da água de forma racional e sustentável. Nesse sentido, a adoção de um valor econômico para tal recurso também se dá no propósito de prevenção de possíveis hiper-explorações. Essa Conferência aborda ainda dois princípios relevantes, sendo eles o estabelecimento de gerenciamento pautado em abordagem participativa, e garantia da inserção das mulheres em todos os níveis relativos à gestão hídrica. Denota-se então caráter social nas referidas discussões.

A gestão hídrica é para Setti et al (2000) “[...] a forma pela qual se pretende equacionar e resolver as questões de escassez relativa dos recursos hídricos, bem como fazer o uso adequado, visando a otimização dos recursos em benefício da sociedade". (SETTI et al, 2000, p. 45). Entende-se que a crescente demanda e complexidade da gestão dos recursos hídricos vem exigindo além da mobilização política, acadêmica, dos usuários, dentre outros, a procura de novos métodos e tecnologias de aproveitamento da água. Nesse contexto, o planejamento então,

[...] teria como função avaliar as demandas e as disponibilidades desses recursos em horizontes de tempos futuros, buscando sua alocação entre os múltiplos usos das águas, visando conseguir o máximo de ganhos econômicos e sociais com a mínima degradação ambiental (ORLANDO, 2006. p. 116).

Em linhas gerais, fica-se evidente que a noção de gestão e distribuição/controle das águas anda atrelada e sua separação pode acarretar o não entendimento das relações espacialmente instauradas. Elas ajudam a explicar o interesse e a funcionalidade de estudos interventivos, o que não se limita aos estudos de cunho ambiental. Raffestin afirma que "Na gestão da água, o controle e/ou posse desse bem, são, sobretudo de natureza política, pois interessam ao conjunto de uma coletividade" (RAFFESTIN, 1993, p. 231).

Trabalhar com tal tema parece-nos relevante para a sociedade moderna e mais ainda nos territórios onde o uso racional torna-se uma questão de sobrevivência, pois como afirma Bressan (1996), 
Totalidade, racionalidade e controle público. Estes são os elementos decisivos para a estruturação de um modelo de gestão ambiental que seja capaz de reconhecer o meio natural em seu valor intrínseco e, ao mesmo tempo, em seu valor de interesse para o progresso da sociedade humana. A materialização dessa ideia depende da compreensão da natureza como bem público e, por consequência, da capacidade do Estado e das organizações comunitárias em assumir seus papeis de gestores do patrimônio natural num contexto de transformações sociais; depende, igualmente, da identificação ou geração de mecanismos científicos e tecnológicos que tenham, como premissas, o tratamento integral do espaço e de seus ecossistemas (BRESSAN, 1996, p. 75).

A defesa de mecanismos que sirvam como gerenciadores e fiscalizadores das ações em questão, apresenta-se então como elemento para garantir a qualidade e quantidade de água para a população do presente e do futuro. Na perspectiva de uso e qualidade das águas, Botelho (2007) afirma que:

\begin{abstract}
A conscientização, cada vez maior, por parte da sociedade, da importância da água, essencial à vida e a muitas das atividades humanas, impulsionou o desenvolvimento de estudos e a criação de leis, em âmbito federal, estadual e municipal, de regulamentação do uso dos recursos hídricos (BOTELHO, 2007, p. 153).
\end{abstract}

Os aspectos de qualidade e quantidade não podem ser percebidos de forma dissociada, uma vez que a água pode sofrer alterações por condições naturais, pela demanda de núcleos urbanos, das indústrias, atividades agrícolas, mineração entre outros. Segundo Lanna "O padrão qualitativo das águas, tanto quanto o quantitativo, deve ser objeto de consideração e de adequação das disponibilidades com as demandas. Afinal, não basta a água estar disponível na quantidade certa: a qualidade também importa" (LANNA, 1997, p. 16).

Dessa forma, no que tange aos diferentes níveis de disponibilidade de água, Lanna (1997), chama a atenção para o fato de que em certas ocasiões existe:

[...] a possibilidade de que as disponibilidades em determinado período de tempo sejam suficientes para satisfazer as demandas no mesmo período, referindo-se a questões quantitativas apenas. No entanto, existem subperíodos, internos ao período mencionado, nos quais esta situação não ocorre e há carência de água. Obviamente, neste caso deverão existir subperíodos com excesso de água. A solução do problema anterior pode ser encontrada, como foi antes, pela busca de fontes hídricas que serão utilizadas em outros locais durante os subperíodos de escassez (LANNA, 1997, p. 15-16). 
Uma das questões envolvidas na apropriação dos recursos hídricos pode ser entendida através da compreensão da diversidade ambiental, que basicamente possui características e dinâmicas próprias, exigindo assim, técnicas e tecnologias por vezes distintas, a depender de cada realidade.

\title{
Espaço urbano e consumo de água
}

O homem e a natureza desde os primórdios dos tempos estabelecem uma intrínseca relação, de acordo com o nível técnico dos grupos ou sociedades instaladas no espaço geográfico se intensificam as relações estabelecidas com o ambiente, alterando o nível de exploração e dependência dos recursos naturais, nesse sentido Setti et al (2001) assevera que,

\begin{abstract}
As atitudes do homem em relação à terra e ao meio ambiente têm variado através do tempo, entre regiões e culturas. O homem primitivo, com alguns povos remanescentes no século XX, temia e respeitava a natureza, por considerá-la sinônimo de Deus. No mundo atual, as abordagens sobre o meio ambiente têm uma grande variação, desde a exploração máxima, onde o foco encontra-se no retorno econômico, até a visão completamente preservacionista dos mais extremados ecologistas (SETTI et al, 2001, p. 14).
\end{abstract}

A relação entre sociedade e natureza não pode ser entendida como homogênea em se tratando dos diferentes períodos históricos, ou mesmo em um único período, dessa forma, é possível observar nessa dualidade momentos de maior ou menor pressão humana sobre os recursos naturais. $\mathrm{Na}$ atualidade, existem possibilidades reais de inversão desse cenário, entretanto, mesmo vivendo no que se pode chamar de "era da informação e do conhecimento", tendo em vista o nível técnico e informacional (SANTOS, 2006), são diversos e muito claros os exemplos de situações contraditórias sobre a perspectiva organizacional como a desigualdade e pouco planejamento das cidades no Brasil e no mundo. Nesse quesito, os recursos naturais, principalmente os hídricos, são vistos de forma funcionalista, o seu sentido mais forte aparece no atendimento das necessidades instauradas, que em muitos casos permeia apenas relações econômicas.

A instauração de atos de "planejamento" que não contemple o complexo de relações sociais, econômicas, políticas e naturais do momento pode acarretar uma série 
de problemas futuros, como a escassez, conflitos locais, dificuldades relacionadas à saúde, migração, fuga de investimentos privados, degradação ambiental, entre outros.

Segundo Rocha (2011),

Nos últimos anos, o homem tem participado como agente acelerador dos processos de desequilíbrio da paisagem, especialmente pelas atividades produtivas diretamente desenvolvidas nas bacias hidrográficas. A escassez dos recursos naturais, especificamente dos recursos hídricos, gera problemas de ordem econômica, política e social, daí a necessidade de um plano de desenvolvimento sustentável e de gestão ambiental (ROCHA, 2011, p. 10).

Tais planos devem considerar não somente os espaços com maior grau de estabilidade dos recursos naturais, mas também as áreas antropizadas, nesse sentido, a cidade (urbano) ganha certa importância. O urbano, que pode ser compreendido como síntese dos processos de produção do espaço, que apesar de uma fragmentação, comporta-se de forma articulada e fluida. Segundo Corrêa (2002),

Vista como uma forma de organização do espaço pelo homem, a cidade pode ser considerada, de acordo com Harvey, como a expressão concreta de processos sociais na forma de um ambiente físico construído sobre o espaço geográfico. Expressão de processos sociais, a cidade reflete as características da sociedade (CORRÊA, 2002, p. 121).

Compreende-se então que a construção desse espaço está intimamente relacionada com o social. A produção e consumo do espaço produzido não se dá de forma aleatória ou mesmo descompromissada, pelo contrário, a estruturação do urbano, apesar da existência de ações desconexas, efetiva-se sob os interesses e intencionalidades de agentes sociais concretos. Para Corrêa “[...] É consequência da ação de agentes sociais concretos, históricos, dotados de interesses estratégias e práticas espaciais próprias, portadoras de contradições e geradores de conflitos entre eles mesmos e com outros segmentos da sociedade" (CORRÊA, 2011, p. 43).

Decorrente da associação dos homens com suas manifestações materiais e imateriais na paisagem a cidade surge enquanto elemento marcante (noção de núcleos urbanos). Boa parte das relações compreendidas entre os homens e o meio reflete substancialmente na qualidade de vida da população e do ambiente. O urbano torna-se foco de discussões justamente por apresentar uma maior fragilidade estrutural, tanto no 
que se refere à base física, quanto nas disposições políticas, que por muito, não atendem as demandas sociais. Nela refletem discussões sobre o preço da água, saneamento básico, consumo de energia e resíduos sólidos.

Para Pereira Junior (2004),

O saneamento básico não acompanhou o crescimento das cidades. Cerca de $90 \%$ da população urbana brasileira é servida por sistemas de abastecimento de água, mas apenas cerca de $66 \%$ dispõe de redes de coleta de esgoto sanitários, dos quais menos de $25 \%$ recebe algum tratamento antes da disposição final. Em relação ao lixo, a situação é semelhante: a maior parte dos quase 12.00 locais onde os Municípios brasileiros dispõem seus resíduos sólidos são corpos de água e vazadouros, ou "lixões" a céu aberto, que acarretam a poluição e a contaminação dos corpos de água próximos. São poucos os Municípios nos quais o lixo é tratado adequadamente, mediante disposição em aterros sanitários, incineração ou compostagem (PEREIRA JUNIOR, 2004, p. 12).

A qualidade das águas deve ser compreendida como parâmetro base na gestão dos recursos hídricos. Isso deve-se em parte por sua ligação com a qualidade de vida das populações que se servem de tal recurso. Na verdade, os recursos hídricos têm capacidade de se recuperar de diversos processos contaminadores, mediante processos físicos químicos e biológicos. Entretanto, essa capacidade não pode ser vista em todas as situações, pois irão variar de acordo com nível de alteração das características naturais e tecnologias empregadas no processo de alteração/apropriação do espaço.

\section{Múltiplos usos da água}

No que se refere à complexidade das decisões que fazem parte da Engenharia de Recursos Hídricos, Lanna (1997), afirma que tal complexidade decorre tanto das diferentes possibilidades de suprimentos às demandas quanto das variabilidades destas demandas. $\mathrm{O}$ autor (op. cit) organiza as necessidades em três classes principais:

I - Infraestrutura social: refere-se às demandas gerais da sociedade nas quais a água é um bem de consumo final;

II - Agricultura e aquicultura: refere-se às demandas de água como bem de consumo intermediário visando a criação de condições ambientais adequadas para o desenvolvimento de espécies animais ou vegetais de interesses para a sociedade;

III - Industrial: demandas para atividades de processamento industrial e energético nas quais a água entra como bem de consumo intermediário. 
Ainda de acordo com Lanna (1997, p. 17), quanto à natureza da utilização existe três possibilidades: 1) Consuntivo: refere-se aos usos que retiram a água de sua fonte natural diminuindo suas disponibilidades quantitativas, espacial e temporalmente; 2) Não-consuntivo: refere-se aos usos que retornam à fonte de suprimento, praticamente a totalidade da água utilizada, podendo haver alguma modificação no seu padrão temporal de disponibilidade quantitativa; 3) Local: refere-se aos usos que aproveitam a disponibilidade de água em sua fonte sem qualquer modificação relevante, temporal ou espacial, de disponibilidade quantitativa.

Com relação aos usos consuntivos, tidos aqui como de maior relevância haja vista sua maior demanda, bem como potencial de pressão nas condições naturais que influi na dinâmica dos sistemas anteriormente estabelecida. Segundo Tucci (2001), esse tipo de utilização dos recursos hídricos tem como foco principal o abastecimento humano, animal (dessedentação), industrial e irrigação. O gráfico 1, apresenta as diferenças relativas a distribuição de água por tipo de consumo no Brasil.

Gráfico 1- Distribuição de água por tipo de consumo no Brasil

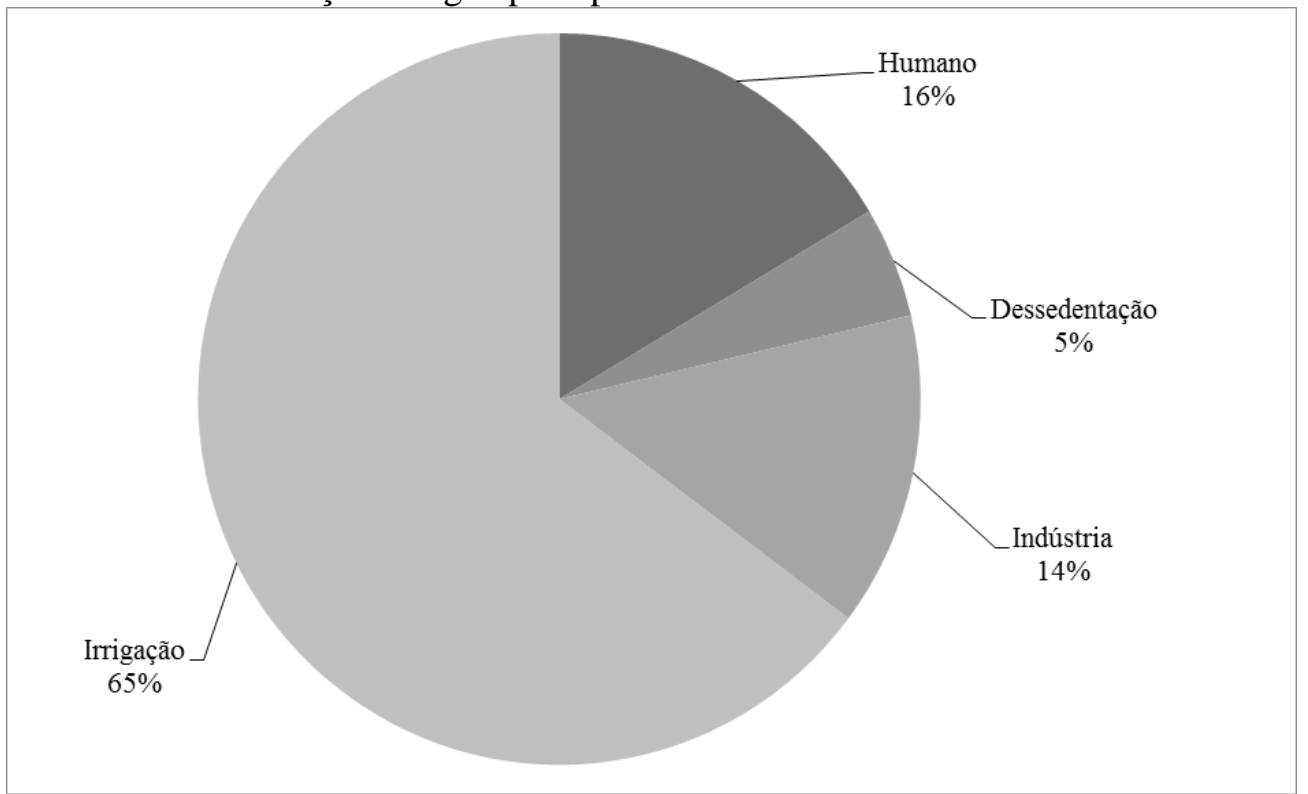

Fonte: Elaborado pelos autores com base em dados de Tucci (2005)

Em uma perspectiva meramente quantitativa, a disponibilidade de água para o consumo humano não representa problema (ao menos não deveria), uma vez que outras variáveis, como é caso da irrigação e uso industrial exigem uma quantidade de água bem superior. Dessa forma, o abastecimento humano, em teoria, não deveria ser tido como algo problemático, mesmo em função de adversidades extremas (variações 
naturais como a precipitação), já que bastaria uma redistribuição de tal recurso de forma a garantir água de forma suficiente.

Nas residências, a água é utilizada para beber, para o preparo de comida, higiene pessoal, saneamento domiciliar, limpeza do vestuário e da moradia, entre outras funções, dependendo dos fatores como cultura, poder aquisitivo, hábitos alimentares e clima. O uso doméstico não é uniforme, pois $4 \%$ da população mundial utiliza mais de 300 litros diários "per capita", enquanto $75 \%$ utiliza menos de 50 litros diários "per capita". Nas áreas urbanas, além do uso doméstico, a água é utilizada em restaurantes, serviços médicos, pequenas indústrias (padarias, pequenas fábricas de comida, etc.), lavanderias, escolas e em outros serviços (PEREIRA JUNIOR, 2004, p. 6).

A área urbana é uma das quais mais irão sofrer com a falta de água, a população lidará, mas não somente no que se refere ao uso diário residencial, pois, como se sabe, outras estruturas também dependem da água para o seu funcionamento, como é o caso da instância industrial e a relacionada com o lazer. Com isso, pensar no gerenciamento hídrico, bem como em planos para o abastecimento urbano torna-se de fundamental importância.

\section{Constatações sobre o abastecimento urbano de água em Lagoa Real - BA}

O município de Lagoa Real localiza-se no semiárido baiano entre as

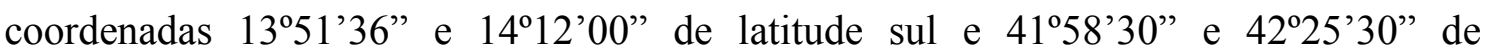
longitude oeste. Discussões inerentes aos recursos hídricos são imprescindíveis para o município, visto suas características naturais que remontam um cenário de escassez periódica (domínio da caatinga), assim como as crescentes demandas pelos múltiplos usos das águas, como o aumento da população e instauração e ampliação estruturas produtivas.

A Lei n. ${ }^{\circ} 5.025$ de 13 de junho de 1989, cria o município de Lagoa Real, decorrente do desmembramento do município de Caetité. Lagoa Real faz divisa com os municípios de Caetité, Brumado, Ibiassucê, Livramento de Nossa Senhora e Rio do Antônio e distancia-se da capital do estado em aproximadamente $730 \mathrm{~km}$. O mapa 1 apresenta os limites atuais de Lagoa Real e municípios vizinhos. 
Mapa 1- Localização do município de Lagoa Real - BA
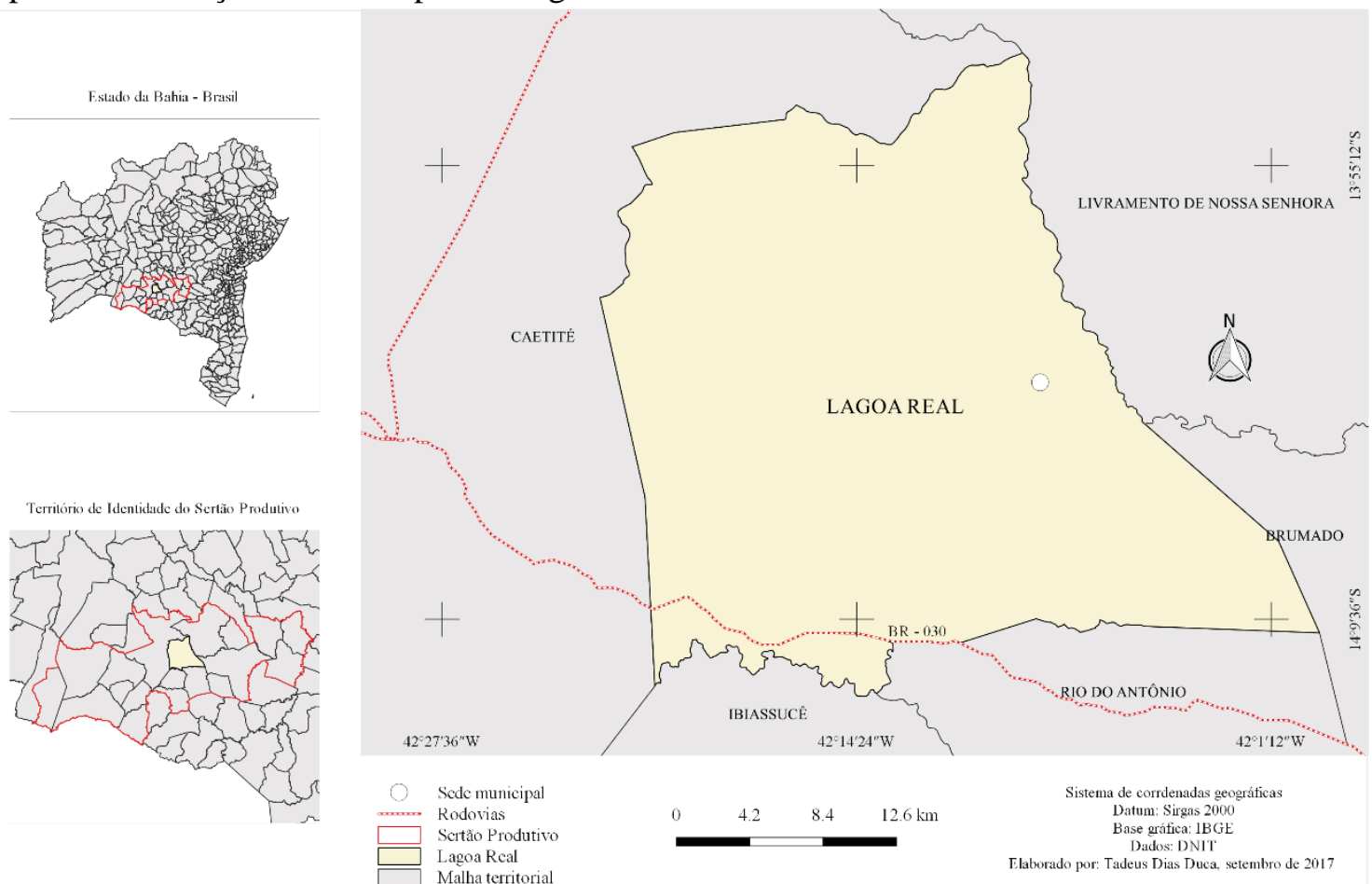

Fonte: Elaborado por Tadeus Dias Duca, 2014.

Na tabela 1, visto a seguir, no ano de 2010 o município detinha pouco mais de 13.900 habitantes, ao longo dos anos apresentados, vê-se um crescimento aproximado de $25 \%$ da população total entre 1991 e 2000, já entre os anos de 2000 e 2010, essa taxa de crescimento ficou entorno de 45\%. Entre 1991 e 2000 houve um crescimento percentual maior da população urbana, o inverso entre os anos de 2000 e 2010.

Tabela 1- População no município de Lagoa Real - Bahia, nos anos de 1991, 2000 e 2010

\begin{tabular}{|l|l|l|l|l|l|}
\hline Ano & População Rural & $\mathbf{\%}$ & População Urbana & \% & Total \\
\hline $\mathbf{1 9 9 1}$ & 6512 & 85,02 & 1148 & 14,98 & 7660 \\
\hline $\mathbf{2 0 0 0}$ & 7599 & 79,11 & 2006 & 20,89 & 9605 \\
\hline $\mathbf{2 0 1 0}$ & 11126 & 79,84 & 2808 & 21,16 & 13934 \\
\hline
\end{tabular}

Fonte: Censos do IBGE, 1991 a 2010

O gráfico 2 apresenta a variação da população urbana atendida com água entre os anos de 2005 - 2011, algo interessante, principalmente no que se refere ao processo de gestão hídrica, já que o avanço/retrocesso da população é tido como elemento essencial para o estabelecimento de estratégias de atendimento/prestação de serviços. Com isso, devem-se elaborar planos condizentes com a situação local visando o uso racional da água por parte da população, haja vista um decréscimo da parcela que reside na área urbana, bem como maior pressão no sistema de abastecimento, nesse caso, 
levando em consideração a necessidade de ampliação do oferecimento de tal recurso, deve-se atentar não só com os padrões de quantidade, mas também de qualidade.

Gráfico 2 - População urbana de Lagoa Real abastecida com água entre 2005 e 2011

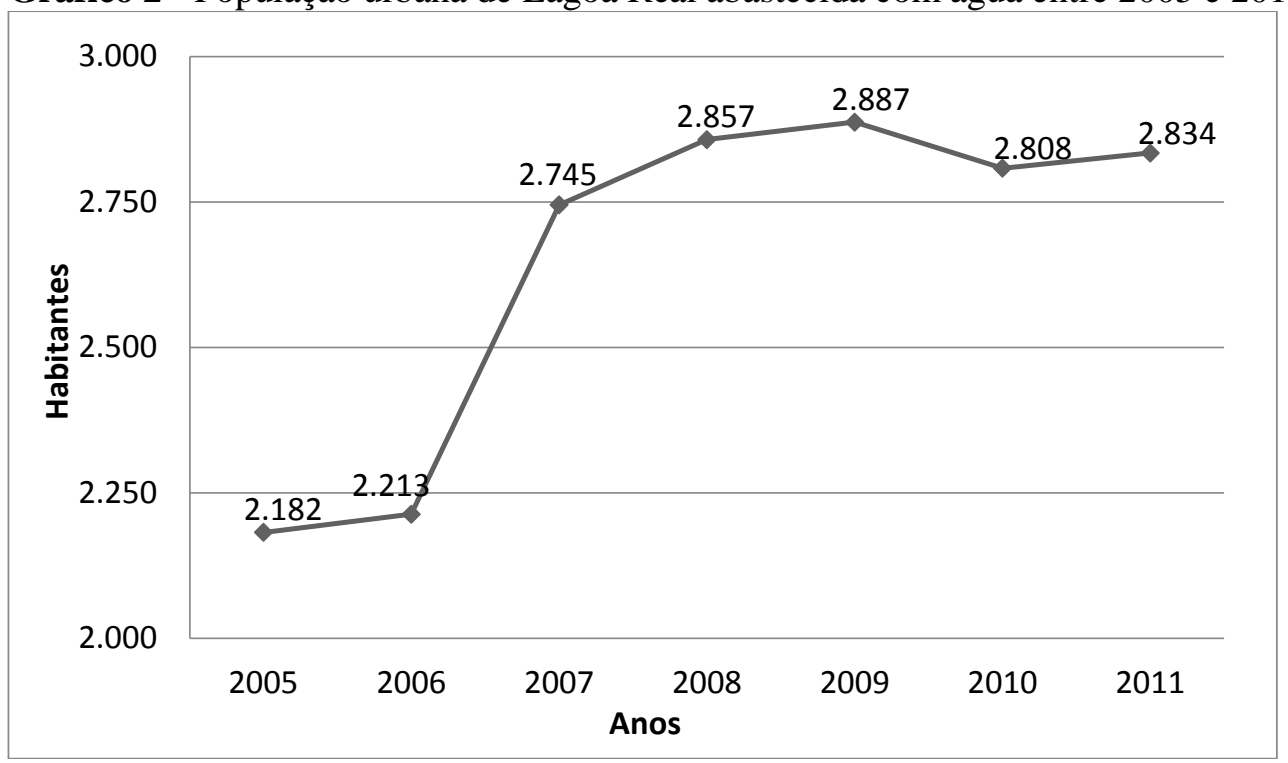

Fonte: adaptado do SNIS (2014)

A variação da população urbana abastecida com água no município de Lagoa Real não atinge taxas alarmantes. Entre os dados apresentados que demonstram respectivamente a menor parcela da população (2005) e a maior (2009) dentro do intervalo de tempo utilizado, a variação populacional apresenta um aumento de cerca de 705 habitantes, valor esse, que apesar de não ser tão elevado, deve ser considerado, principalmente em se tratando de uma cidade pequena.

No intuito de simplificação do gráfico 2, pode-se dividi-lo em duas variáveis, a primeira correspondendo às modificações entre os anos de 2005 - 2007, caracterizadas por uma expansão gráfica vertical acentuada entre os anos de 2006 e 2007, e a segunda variação representando o período que vai de 2007 - 2011, marcada por uma estabilidade nos valores. O gráfico 3 apresenta o consumo médio de água da população entre os anos de 2006 e 2012. 
Gráfico 3 - Consumo médio per capita de água pela população atendida em Lagoa Real

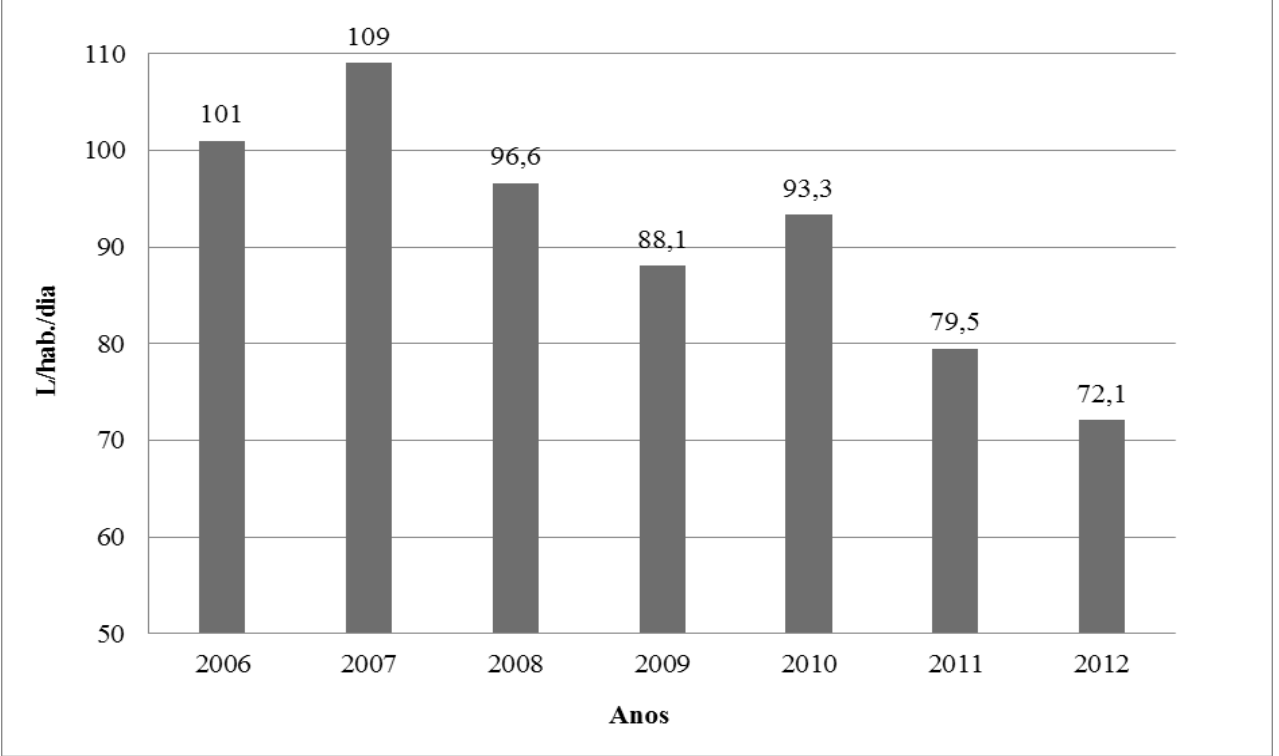

Fonte: adaptado do SNIS (2014)

Entende-se que a maior necessidade/procura por um serviço, somada a uma não ampliação dos recursos disponíveis, gera por consequência uma menor disponibilidade/oferecimento de um recurso. Os gráficos 2 e 3 demonstram que o consumo médio de água litros por habitantes ao dia possui taxas mais expressivas justamente nos períodos em que a população denota valores menores, e o inverso acontece nas demais situações. Quando a população tende a aumentar, diminui-se o oferecimento do recurso, dessa forma, observa-se que ao longo dos anos foram insuficientes as estratégias de oferecimento quantitativo de água para a população, uma vez que o consumo médio per capita tende a cair entre 2006 (101 1/bah. /dia) e 2012 (72,1 1/bah. /dia).

Um dos dados interessantes para o entendimento da lógica de gestão hídrica refere-se ao índice de perdas na distribuição. Como pode ser visto no gráfico 4, o maior percentual de perdas na distribuição, ocorre contraditoriamente ao período em que teoricamente deveria haver um maior controle sobre o panorama hídrico, isso levando em consideração principalmente duas variantes: i) o período de estiagem marcante nos últimos anos no semiárido brasileiro, ii) melhoramento das condições técnicas e financeiras de intervenção das estruturas operacionais. Compreende-se ainda que, entre os anos de 2010 e 2012 tem-se uma curva ascendente com variações de percentual, que no caso dos anos de 2011 e 2012, chegam praticamente a terem seus valores dobrados. 
Gráfico 4 - Índice de perdas na distribuição de água no setor urbano de Lagoa Real - BA

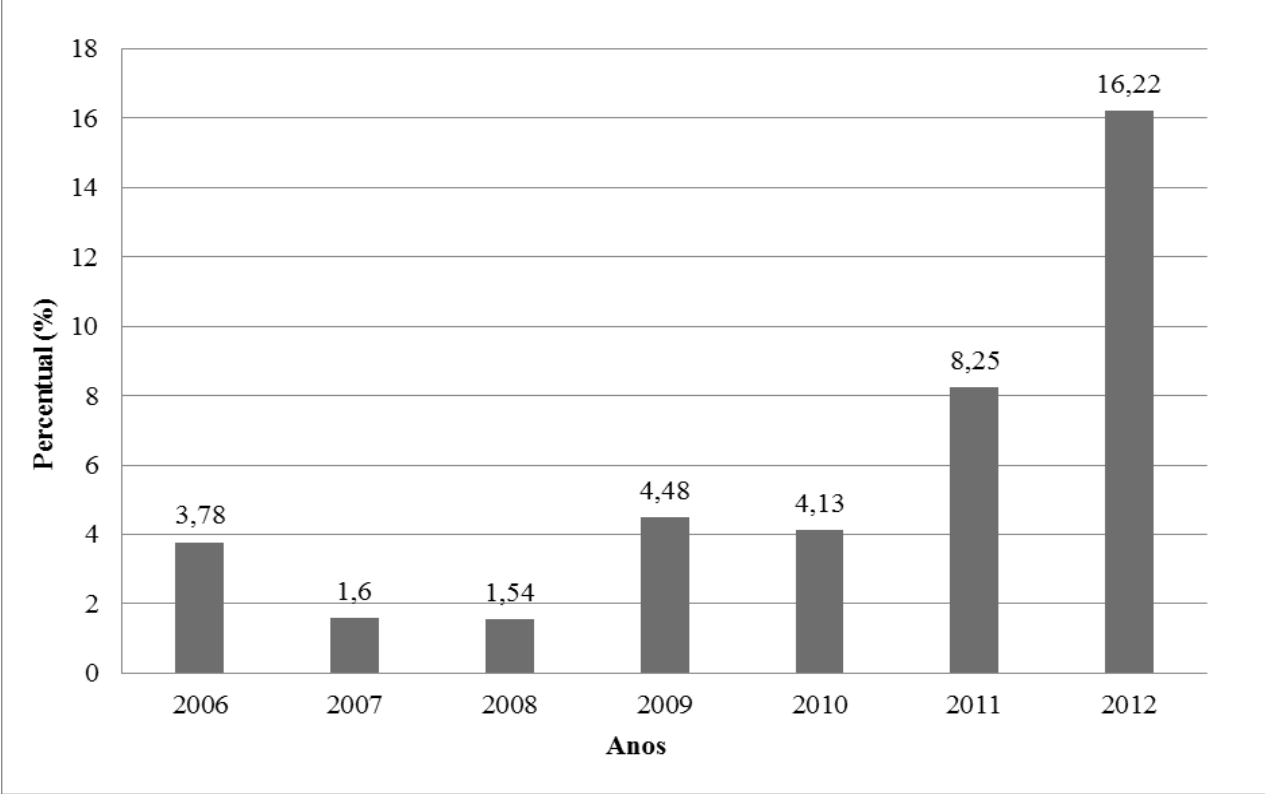

Fonte: adaptado do SNIS (2014)

No que concerne aos indicadores operacionais de desenvolvimento dos sistemas de abastecimento de água, Medeiros (2014) afirma que:

A perda de água na distribuição (que relaciona o volume de água disponibilizado e consumido) para o conjunto de prestadores de serviços que atuam no Semiárido brasileiro foi considerada elevada, alcançando $44,87 \%$. Isto indica que os investimentos em curso ainda não conseguiram reduzir, de maneira significativa as perdas de água dos sistemas. Contudo, na comparação com as perdas de água na região Nordeste $(51,04 \%)$ verificou-se que os sistemas de abastecimento do Semiárido são mais eficientes; já em relação ao do Brasil (38,80\%) a eficiência é 6,07\% menor (SNIS 2003). (MEDEIROS, 2014, p. 63).

Mediante o exposto, entende-se que a eficiência no processo de distribuição, que pode ser ainda ampliado para a noção de captação e tratamento, apresenta-se como um dos problemas a serem discutidos e superados no Brasil. Com base ainda em Medeiros (2014), no que tange a prejuízos na distribuição, de maneira simples, se houvesse uma redução de cerca de $20 \%$ na perda de água nos sistemas de distribuição, levando em consideração aos padrões atuais de consumo per capita de água, teoricamente o número de habitantes com acesso a água poderia ser ampliado em cerca de 5,3 milhões, isso apenas levando em consideração a eficiência do sistema de distribuição de água, sem levar em conta a qualidade de água ofertada. 


\section{Considerações finais}

O gerenciamento de recursos hídricos para o abastecimento urbano é relevante para as sociedades atuais, principalmente para os territórios que apresentam características físico-geográficas de escassez periódica, mal-uso e poluição. A análise referente a importância política dos princípios voltados a gestão hídrica e/ou abastecimento urbano é entendida de modo a compor a base de qualquer ação frente a uma realidade, dessa forma, o seu entendimento e maior utilização prática compõe-se como algo válido.

Levar em conta as questões relativas as peculiaridades do semiárido, estabelecese como elemento essencial no que concerne a melhores resultados, tanto no que diz respeito a gestão dos recursos hídricos, assim como das ações ao abastecimento urbano. Isso se dá em essência, pelas múltiplas e complexas condições ambientais e/ou sociais estabelecidos nos mais variados espaços, o que carece, dentre outras coisas, de ações particulares e bem localizadas.

Com base no levantamento, tratamento e análise dos dados de Lagoa Real - BA entende-se que os resultados alcançados foram diversos e ao mesmo tempo importantes para a pesquisa. Quanto aos objetivos propostos para esse trabalho, considera-se que foram até certo ponto alcançados com sucesso.

Com relação a Lagoa Real, verifica-se uma estagnação nas melhorias/ampliação no sistema de abastecimento urbano de água, para tal consideração, têm-se como base os diversos dados apresentados graficamente. Como é o caso da variação populacional estabelecida entre os anos de 2005 e 2011 , teve quantitativamente e qualitativamente a disponibilidade de água afetada pelas configurações adotadas no processo de gerência e/ou variações nos índices de precipitação.

Nesse sentido, existem discrepâncias no que se refere a realidade e as condições básicas atribuídas, tanto ao processo de gestão hídrica, quanto de abastecimento em Lagoa Real, isso levando em consideração que os mesmos devem ser realizados sempre entendendo como essencial a garantia de qualidade e quantidade de água disponível a população.

\section{Referências}

ABRH. Associação Brasileira de Recursos Hídricos. Disponível em: $<$ http://www.abrh.org.br/SGCv3/index.php?P1=2\&P2=3\&P1T=institucional \&P2T=que m_somos $>$. Acesso em: 13 abr. 2014. 
BAHIA, Decreto ${ }^{\circ} 12.354$ de 25 de agosto de 2010. Institui o Programa Territórios de Identidade. Disponível em: <http://governo-

ba.jusbrasil.com.br/legislacao/1024959/decreto-12354-10>. Acesso em: 07 nov. 2014.

BAHIA. Lei no 5.025 de 13 de junho de 1989. Cria o município de Lagoa Real, desmembrado do município de Caetité. Casa Civil. Disponível em: < http://www.legislabahia.ba.gov.br/>. Acesso em: 14 out. 2013.

BOTELHO, Rosangela Garrido Machado; SILVA, Antônio Soares da. Bacia Hidrográfica e Qualidade Ambiental. In. VITTE, Antônio Carlos; GUERRA, Antônio José Teixeira (Org.). Reflexões sobre a geografia física no Brasil. ed. 2. Rio de Janeiro: Bertrand Brasil, 2007.

BRASIL. Lei $\mathrm{n}^{\circ} 11.445$, de 5 de janeiro de 2007. Estabelece diretrizes nacionais para o saneamento básico: Casa Civil, 2007. Disponível em: < http://www.planalto.gov.br/ccivil_03/_ato2007-2010/2007/lei/111445.htm>. Acesso em: 21 jul. 2014.

BRASIL. Lei no 9433, de janeiro de 1997. Institui a Política Nacional de Recursos Hídricos, cria o Sistema Nacional de Gerenciamento de Recursos Hídricos. Disponível em: < http://www.planalto.gov.br/ccivil_03/leis/19433.htm>. Acesso em: 13 mar. 2014.

BRESSAN, Delmar. Gestão racional da Natureza. São Paulo: Hucitec, 1996.

CORREAA, Roberto Lobato. Processos Espaciais e a Cidade. In. Trajetória Geográfica. Rio de Janeiro: Bertrand, 2002.

CORRÊA, Roberto Lobato. Sobre Agentes sociais, escala e produção do espaço: um texto para discussão. In. CARLOS, Ana Fani Alessandri, SOUZA, Marcelo Lopes e SPOSITO, Maria Encarnação Beltrão (Organizadores). A produção do espaço urbano: agentes e processos, escalas e desafios. São Paulo: Editora Contexto, 2011.

DECLARAÇÃO de Dublin. 1992. Disponível em: < http://www.meioambiente.uerj.br/emrevista/documentos/dublin.htm>. Acesso em: 29 abr. 2014.

IBGE. Área Territorial Brasileira. 2010. Disponível em: <http://www.ibge.gov.br/home/geociencias/cartografia/default_territ_area.shtm $>$. Acesso em 15 de Fev./2014.

LANNA, Antonio Eduardo. Introdução. In. PORTO, Rubem La Laina (org.) et al. Técnicas quantitativas para o gerenciamento de recursos hídricos. Porto Alegre: Ed. Universidade/UFRGS/Associação Brasileira de Recursos Hídricos, 1997.

MEDEIROS, Salomão de Souza [et al]. Abastecimento urbano de água: panorama para o semiárido brasileiro. Campina: INSA, 2014.

MIRANDA, Graziele Muniz. Indicadores do Potencial de Gestão Municipal de Recursos Hídricos. 2012. 96 f. Tese (Mestrado em Geografia) - Instituto de Geociências e Ciências Exatas, Universidade Estadual Paulista, São Paulo - Rio Claro. 2012. 
ORLANDO, Paulo Henrique Kingma. Produção do espaço e gestão hídrica na Bacia do Rio Paraibuna (MG - RJ): uma análise crítica (tese de doutorado). Presidente Prudente: [s.n], 2006.

PEREIRA JUNIOR, José de Sena Pereira. Recursos hídricos: conceituação, disponibilidade e usos. Brasília - DF: Câmara dos Deputados, 2004.

RAFFESTIN, Claude. Por uma geografia do poder. São Paulo: Ática, 1993.

ROCHA, Altemar Amaral. Sociedade e natureza: A produção do espaço urbano em bacias hidrográficas. Vitória da Conquista: Editora da UESB, 2011.

ROCHA, Gerôncio de Albuquerque et al. Recursos Hídricos. São Paulo: SMA/CEA, 2011.

SANTOS, Milton. O Brasil: território e sociedade no início do século XXI. 9. ed. Rio de Janeiro: Record, 2006.

SETTI, Arnaldo Augusto. et al. Introdução ao Gerenciamento de Recursos Hídricos. 2. ed. Brasília: Agência Nacional Elétrica, Superintendência de Estudos e Informações Hidrológicas, 2000.

TUCCI, C. E. M. et al. Gestão da Água no Brasil. Brasília: UNESCO, 2001.

Recebido em: 18/11/2017

Aceito para publicação em: 10/12/2017 